\title{
Work Statement
}

Field Test of a Catalytic Combustion System for Non-Ammonia Control of Gas Turbine NOx Emissions (Task 1)

Under federal Award/Proposal Number DE-FG26-04NT42078, the California Energy Commission (CEC) will subgrant $\$ 100,000$ to the City of Riverside, California, where the project will be located. In turn, the City of Riverside will subaward the federal funds to Alliance Power and/or Catalytica Energy Systems, Inc. (CESI).

\section{Technical Task 1: Design, Fabricate and Engine Test Xonon Modules}

Alliance Power will coordinate administrative and management activities associated with this task to ensure compliance with CEC grant requirements.

CESI will design and fabricate two Xonon ${ }^{\mathrm{TM}}$ modules according to General Electric (GE) specification for operating conditions in the GE-10 gas turbine. CESI will ship the modules to the GE test facility for engine testing. CESI will provide test personnel as required to oversee the installation, testing and removal of the Xonon modules.

GE will perform an engine test of the CESI-supplied Xonon modules on a GE-10 test engine in the fall of 2004. GE will record all test data as appropriate to evaluate the emissions and operating performance of the Xonon module. Following the test, GE will provide a letter report of the engine test findings. The letter report shall summarize the testing and provide an assessment of Xonon's ability to ultimately achieve less than 3 ppm NOx emissions on the GE-10. All expenses incurred by GE for this task will be paid by GE; no federal funds will be used.

Following the reporting of findings, GE will make a decision whether or not to proceed with the Riverside retrofit project. GE will write a letter to CESI giving their decision. GE and CESI will report of engine test findings and the decision letter to the CEC Project Manager.

\section{Deliverables:}

Letter report of engine test findings, and GE's written decision about whether or not to proceed with the project. 
August 24, 2005

Alliance Power, Ine. 8022 South Grant Way Littleton, Colorado 80122

Attention: $\quad$ Mr. Bruce L. Pohlman, P.E. Project Manager

Subject: $\quad$ City of Riverside, CA

Xonon Retrofit Project

Dear Bruce,

Following is a letter report summarizing the results and analysis of the January 2005 testing of the Xonon equipped GE10 gas turbine combustion system.

Program Background

Since 1998, the General Electric Company (GE) and Catalytica Energy Systems, Inc. (CESI) have collaborated on the application of CESl's Xonon ${ }^{\mathrm{TM}}$ Cool Combustion technology to those GE combustion gas turbines that use "can" type combustors. The Xonon ${ }^{\mathrm{TM}}$ Development Program was transferred to GE's Italian subsidiary Nuovo Pignone (NP) in 1999 to incorporate the Xonon ${ }^{\text {TM }}$ catalytic combustion technology to the $10-\mathrm{MW}$ GE10 combustion gas turbine, an industrial turbine originally developed by NP using GE technology.

Initial project milestones included development of a conceptual design for incorporating the Xonon ${ }^{\mathrm{TM}}$ catalytic combustion technology into the GE10, followed by a comprehensive preliminary design review completed in March, 2003. Extensive combustor tests of the catalytic system on a GE10 combustor were conducted in July through November of 2003 and again in February, 2004. Following successful completion and evaluation of the combustor tests, a full-scale test of the combustion system on a complete GE10 turbine package was planned. The test was initiated in July 2004 and successfully achieved a "full-speed, no-load" condition before a generator malfunction ended the testing. Further full-system turbine testing was conducted in January 2005 in Florence, Italy, and the results are briefly discussed below.

Xonon ${ }^{\mathrm{TM}}$ Program Goals

The main goals of GE's Xonon ${ }^{\mathrm{TM}}$ Development Program are as follows: 
Alliance Power Inc.

Attn: B. Pohiman

Page 2

- Ultra low NOx emissions NOx between $50 \%$ and $100 \%$ of full output over an ambient air temperature range of $-8 \mathrm{C}$ to $49 \mathrm{C}$ :

- Dry system (i.e., no water required to achieve NOx levels)

- Catalyst life of 8000 hours

- Normal turbine maintenance schedule

The goal of the January 2005 full-scale test of the Xonon ${ }^{\text {TM }}$ combustion system on a GE-10 turbine was to investigate the NOx emission performance under a range of operating output levels (i.e., $50 \%$ to $100 \%$ output) for the GE10 turbine. In addition, the testing was also intended to investigate the performance of several design refinements to the Xonon ${ }^{\mathrm{TM}}$ catalytic combustion system developed in response to the prior combustor tests.

Testing Conclusions

Full-scale turbine tests were conducted at ambient temperature conditions of 2 to $10 \mathrm{C}$ during January in Florence, ltaly. The test turbine was started twenty (20) times and run for 60 hours of load testing, which yielded a total of 175 test points. Load levels tested included $50,80,90$, and $100 \%$ of full output. In addition, testing was performed with and without some of the design refinements developed from the prior combustor testing.

The test turbine achieved reliable start-up, successfully starting 20 out of 20 start attempts. Ultra-low NOx levels were achieved at 100\% output at low ambient temperature conditions $(2-10 \mathrm{C})$. As a result, the viability of eatalytic combustion technology on combustion gas turbines in the 10-MW class was demonstrated.

However, additional fundamental system development needs related to the combustion and controls systems to maintain performance as the $\mathrm{X}_{\text {onon }}{ }^{\mathrm{T}}$. catalyst ages are required. Further assessment of catalyst durability is also needed, as well as additional reliability improvements of non-catalytic controls components.

\section{Conclusion}

Based on the results of the January 2005 testing, the Xonon ${ }^{T M}$ catalytic combustion technology can achieve ultra-low NOx emission levels at full-load conditions. However, GE has determined that further design developments to address performance reliability, combustion design and a further understanding of how the catalyst ages are needed before a long-term field demonstration test can be pursued. At this time, GE considers a field demonstration project in the near future to be premature. Therefore, GE respectfully declines moving forward with the GE10 Xonon ${ }^{\mathrm{TM}}$ Retrofit Project for the City of Riverside.

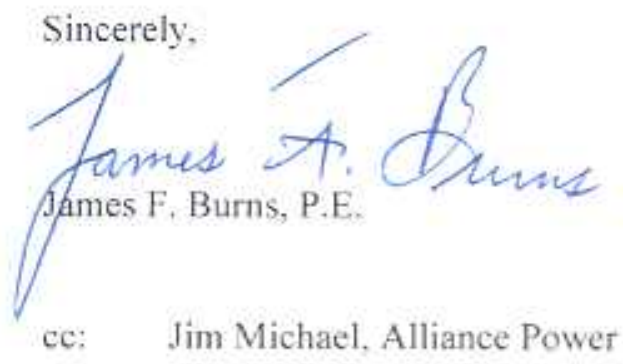

